\section{Isolation of Abikoviromycin and Dihydroabikoviromycin as Inhibitors of Polyketide Synthase Involved in Melanin Biosynthesis by Colletotrichum lagenarium}

\author{
Hiroki Maruyama, Susumu Okamoto, Yasuyuki Kubo ${ }^{\dagger}$, \\ GENTO TSUJI ${ }^{\dagger}$, IsaO FuJII ${ }^{\dagger \dagger}$, YUTAKa EBIZUKA ${ }^{\dagger \dagger}$, \\ KeIKO FURIHATA $^{\dagger \dagger}$, YOICHI HaYaKaWA ${ }^{\dagger \dagger}$, \\ HiROMICHI NAGASAWA and \\ SHOHEI SAKUDA*
}

Department of Applied Biological Chemistry, Graduate School of Agricultural and Life Sciences, The University of Tokyo, Bunkyo-ku, Tokyo 113-8657, Japan

${ }^{\dagger}$ Faculty of Agriculture, Kyoto Prefectural University, Shimogamo, Kyoto 606-8522, Japan

${ }^{\dagger+}$ Graduate School of Pharmaceutical Sciences, The University of Tokyo, Bunkyo-ku, Tokyo 113-0033, Japan

${ }^{\dagger+\dagger}$ Institute of Molecular and Cellular Biosciences, The University of Tokyo, Bunkyo-ku, Tokyo 113-8657, Japan

(Received for publication June 25, 2003)

Many fungi are known as producers of pentaketidederived melanin. This melanin is a polymer of 1,8dihydroxynaphthalene (1,8-DHN). In some fungal pathogens such as Colletotrichum lagenarium and Magnaporthe grisea, melanization of appressoria is essential for penetration into the host plant. ${ }^{1)}$ Fungal conidia germinate and the tips of germ tubes differentiate into appressoria, which synthesize melanin. The melanin mediates the buildup of pressure in the appressorium and this high pressure provides the essential driving force for mechanical penetration into the host plant. ${ }^{2)}$ Blocking of the melanin biosynthesis renders the fungus unable to generate the high pressure required for host leaf penetration by appressoria. Since melanin production is not essential for the growth of the fungus, melanin is an ideal target for the development of an effective drug to protect host plants from infection of pathogens. ${ }^{3)}$

The biosynthesis of 1,8-DHN has been studied well and the pathway was clarified as shown in Fig. $1{ }^{4)}$ In the pathway, 1,8-DHN is biosynthesized via four biosynthetic intermediates, 1,3,6,8-tetrahydroxynaphthalene $\quad(1,3,6,8$ THN), scytalone, 1,3,8-trihydroxynaphthalene (1,3,8-THN) and vermelone (Fig. 1). As the first step, 1,3,6,8-THN is formed from five molecules of malony-CoA by the action of a polyketide synthase. ${ }^{5)}$ Then, 1,3,6,8-THN is reduced and dehydrated successively to afford 1,3,8-THN. Similar reactions are followed for the conversion of 1,3,8-THN to 1,8-DHN. Enzymes involved in this melanin biosynthetic pathway are important as targets to inhibit melanin production selectively. To date, reductase inhibitors, such as tricyclazole and pyroquilon, and dehydratase inhibitors, such as carpropamid and diclocymet, have been actually applied to control rice blast disease (Fig. 1). ${ }^{3)}$ Inhibitors of a polyketide synthase involved in the pathway may also be possible candidates as effective drugs for inhibition of melanin production. However, no specific inhibitor of the enzyme has been obtained. Recently, in vitro reaction system of PKS1, the polyketide synthase of $C$. lagenarium, was developed with the enzyme produced by Aspergillus oryzae in which the PKS1 gene was expressed. ${ }^{6}$ This allowed us to start the screening search for PKS1 inhibitors by using the enzyme reaction system. During the course of the screening among metabolites of microorganisms, we found that Streptomyces sp. No. 4a produced PKS1 inhibitors, and abikoviromycin (1) and dihydroabikoviromycin (2) were isolated from the culture filtrate of the strain as active principles. In this paper, we describe the isolation and biological activity of $\mathbf{1}$ and $\mathbf{2}$ as inhibitors of PKS1.

PKS1 activity was measured with the reaction mixture containing the enzyme produced by $A$. oryzae $\mathrm{M}-2-3$ and malonyl-CoA according to the method described previously. ${ }^{7)}$ After incubation of the reaction mixture with or without a sample, 1,3,6,8-THN produced was converted to its stable oxidation product (flaviolin) by boiling. PKS1 inhibitory activity of a sample was judged from the amount of flaviolin produced, which was measured by TLC (silica gel, Merck No. 105554, $\mathrm{CHCl}_{3}: \mathrm{MeOH}=8: 2$, Rf 0.27) or HPLC (column: Senshu-Pak ODS-H-1151 $\mathrm{C}_{18}, 4.6 \times$ $150 \mathrm{~mm}$, Senshu Kagaku, maintained at $40^{\circ} \mathrm{C}$; mobile phase: gradient elution of $5 \sim 35 \% \mathrm{CH}_{3} \mathrm{CN}$ in $0.1 \% \mathrm{TFA}$ in 21 minutes; flow rate: $1.0 \mathrm{ml} /$ minutes; detection: $\mathrm{UV}$ at $305 \mathrm{~nm}$; retention time: 20.0 minutes). By using this assay system, Streptomyces sp. No. 4a, which was newly isolated from a soil sample collected in Bunkyo-ku, Tokyo, was selected as a producer of a PKS1 inhibitor.

Streptomyces sp. No. 4a was cultured in a Bennet medium for 4 days at $26.5^{\circ} \mathrm{C}$. The $\mathrm{pH}$ of the culture filtrate obtained (3 liters) was adjusted to 12 and the filtrate was extracted with $\mathrm{CHCl}_{3}$. PKS1 inhibitory activity was

\footnotetext{
* Corresponding author: asakuda@mail.ecc.u-tokyo.ac.jp
} 
Fig. 1. Biosynthesis of fungal melanin and inhibition sites of inhibitors.

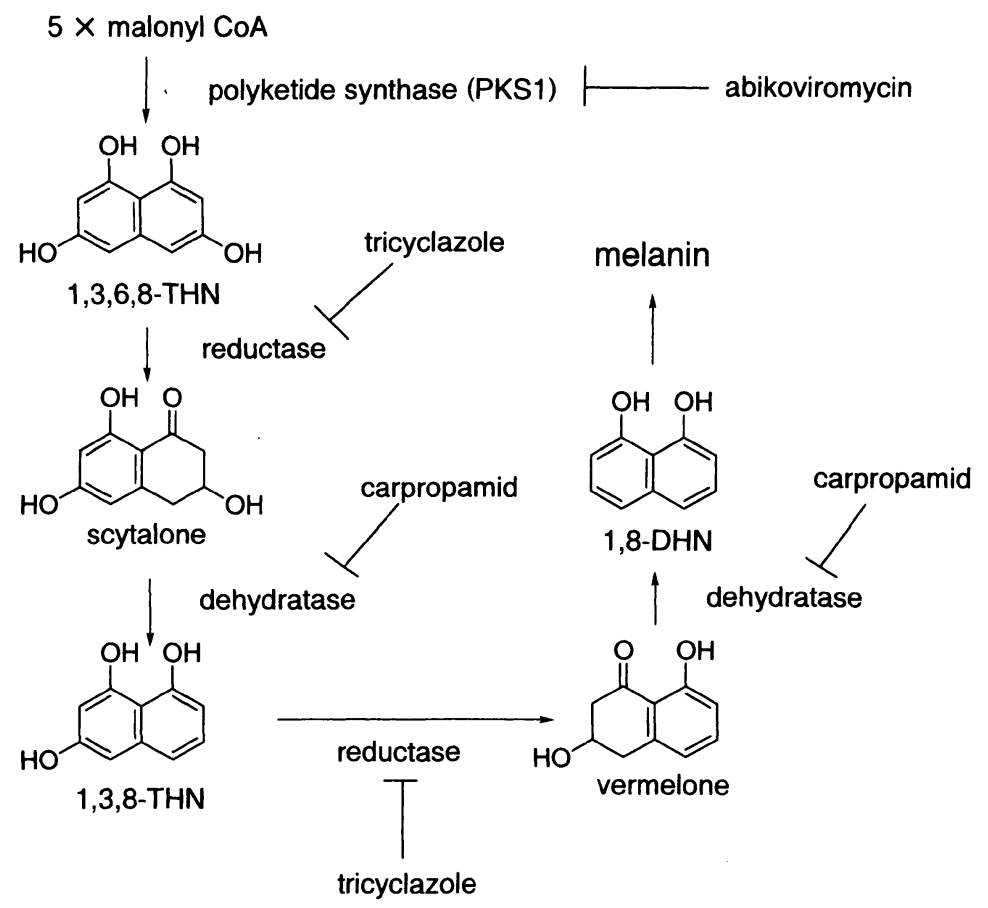

recovered in the $\mathrm{CHCl}_{3}$ extracts $(167 \mathrm{mg})$. The extracts were purified by silica gel column chromatography with $\mathrm{CHCl}_{3}: \mathrm{MeOH}(95: 5)$ (column: $2.0 \times 20 \mathrm{~cm}$, Wakogel C200) to obtain two active fractions. The former fraction $(23 \mathrm{mg})$ was further purified by reverse-phase HPLC (column: Capcell Pak $\mathrm{C}_{18}, 10 \times 250 \mathrm{~mm}$, Shiseido; mobile phase: gradient elution of $8 \sim 80 \% \mathrm{CH}_{3} \mathrm{CN}$ in $10 \mathrm{~mm}$ $\mathrm{AcONH}_{4}-\mathrm{NH}_{4} \mathrm{OH}, \mathrm{pH}$ 8.9, in 20 minutes; flow rate: $5 \mathrm{ml} /$ minutes; retention time: 12.4 minutes) to afford 2 (2.4 mg). 2: FAB-MS (NBA matrix) $m / z 164(\mathrm{M}+\mathrm{H})^{+}$; $\left.[\alpha]_{\mathrm{D}}^{22}+269^{\circ}(c) 0.18, \mathrm{MeOH}\right) \quad\left[\right.$ lit. $[\alpha]_{\mathrm{D}}^{22}+276^{\circ}$ (c 1 , $\mathrm{MeOH})]^{8)} ;{ }^{1} \mathrm{H}$ NMR (500 MHz, MeOH-d $) \delta 6.83(1 \mathrm{H}, \mathrm{d}$, $J=6.5 \mathrm{~Hz}, 6-\mathrm{H}), 6.08(1 \mathrm{H}, \mathrm{d}, J=6.5 \mathrm{~Hz}, 7-\mathrm{H}), 5.18(1 \mathrm{H}, \mathrm{q}$, $J=7.5 \mathrm{~Hz}, 8-\mathrm{H}), 3.99$ (1H, s, 7a-H), 3.24 (1H, s, 4-H), 2.97 $(1 \mathrm{H}, \mathrm{dd}, J=6,12 \mathrm{~Hz}, 2-\mathrm{Ha}), 2.73(1 \mathrm{H}, \mathrm{dt}, J=4,12 \mathrm{~Hz}, 2-$ $\mathrm{Hb}), 2.08(2 \mathrm{H}, \mathrm{m}, 3-\mathrm{H}), 1.78(3 \mathrm{H}, \mathrm{d}, J=7.5 \mathrm{~Hz}, 9-\mathrm{H}) ;{ }^{13} \mathrm{C}$ NMR (125 MHz, MeOH-d $\left.d_{4}\right) \delta 140.2$ (C-5), 134.2 (C-6), 132.6 (C-7), 117.2 (C-8), 64.5 (C-4a), 63.5 (C-7a), 40.0 (C2), 25.1 (C-3), 14.0 (C-9): On the other hand, the latter fraction $(35 \mathrm{mg}$ ) was purified by normal-phase HPLC (column: Senshu-Pak Aquasil SS-752N, $10 \times 250 \mathrm{~mm}$, Senshu Kagaku; mobile phase: isocratic elution of $n$ hexane : 2-propanol : $\mathrm{H}_{2} \mathrm{O}$ : triethylamine, $70: 30: 1: 0.02$; flow rate: $5 \mathrm{ml} / \mathrm{minutes}$; retention time: 9.0 minutes) to obtain 1 (6.3 mg). 1: FAB-MS (NBA matrix) $m / z \quad 162$
$(\mathrm{M}+\mathrm{H})^{+} ;[\alpha]_{\mathrm{D}}^{20}+67.5^{\circ}(c \quad 0.025,0.1 \mathrm{~N} \mathrm{NaOH})\left[\right.$ lit. $[\alpha]_{\mathrm{D}}^{21}$ $\left.+148.9^{\circ}(c 1,0.1 \mathrm{~N} \mathrm{NaOH})\right]^{9)} ;{ }^{1} \mathrm{H}$ NMR $\left(500 \mathrm{MHz}, \mathrm{CDCl}_{3}\right)$ $\delta 7.43(1 \mathrm{H}, \mathrm{d}, J=6.5 \mathrm{~Hz}, 7-\mathrm{H}), 6.53(1 \mathrm{H}, \mathrm{d}, J=6.5 \mathrm{~Hz}, 6-$ H), $5.50(1 \mathrm{H}, \mathrm{q}, J=7.0 \mathrm{~Hz}, 8-\mathrm{H}), 3.92(1 \mathrm{H}, \mathrm{s}, 4-\mathrm{H}), 3.81$ $(1 \mathrm{H}, \mathrm{dd}, J=5.5,15 \mathrm{~Hz}, 2-\mathrm{Ha}), 3.69(1 \mathrm{H}, \mathrm{dt}, J=5.5,15 \mathrm{~Hz}$, 2-Hb), $2.19(1 \mathrm{H}, \mathrm{m}, 3-\mathrm{Ha}), 1.90(3 \mathrm{H}, \mathrm{d}, J=7.0 \mathrm{~Hz}, 9-\mathrm{H})$, $1.62(1 \mathrm{H}, \mathrm{m}, 3-\mathrm{Hb}) ;{ }^{13} \mathrm{C} \mathrm{NMR}\left(125 \mathrm{MHz}, \mathrm{CDCl}_{3}\right) \delta 172.1$ (C-7a), 142.3 (C-7), 136.5 (C-5), 132.8 (C-6), 119.5 (C-8), 59.5 (C-4), 54.5 (C-4a), 44.5 (C-2), 21.8 (C-3), 14.0 (C-9).

The molecular formula of 2 was estimated as $\mathrm{C}_{10} \mathrm{H}_{13} \mathrm{NO}$ from its FAB-MS and NMR spectra, and detailed analysis of NMR spectra and the optical rotation value led to identification of $\mathbf{2}$ as dihydroabikoviromycin. ${ }^{8,10)}$ Similarly, 1 was identified as abikoviromycin. ${ }^{10,11)}$ The absolute configuration of $\mathbf{1}$ has been determined as shown in Fig. $2,{ }^{11)}$ and it has been shown that the epoxide moiety of $\mathbf{2}$ has the same absolute configuration as that of 1 by conversion experiment from 1 to $2 .^{10)}$ However, stereochemistry at C$7 \mathrm{a}$ of $\mathbf{2}$ has not been determined. In the NOESY spectrum of 2, NOE was not observed between $\mathrm{H}-4$ and $\mathrm{H}-7 \mathrm{a}$, but it was observed between $\mathrm{H}-4$ and one of the methylene protons at C-2 with $\alpha$-configuration and between $\mathrm{H}-7 \mathrm{a}$ and that with $\beta$-configuration as shown in Fig. 2. This determined the absolute configuration at C-7a of $\mathbf{2}$ is $S$.

PKS1 inhibitory activity and antifungal activity toward 
Fig. 2. Structures of abikoviromycin (1) and dihydroabikoviromycin (2).

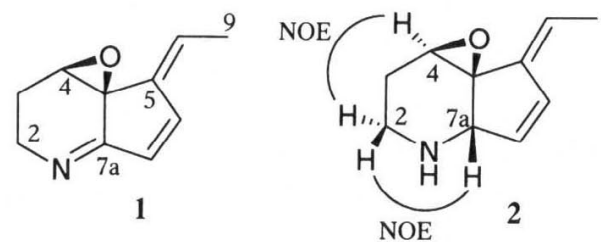

Table 1. PKS1 inhibitory activity $\left(\mathrm{IC}_{50}\right)$ and antifungal activity (MIC) of $\mathbf{1}, \mathbf{2}$ and cerulenin.

\begin{tabular}{ccc} 
Compound & $\mathrm{IC}_{50}(\mu \mathrm{g} / \mathrm{ml})$ & $\mathrm{MIC}(\mu \mathrm{g} / \mathrm{ml})^{\mathrm{a}}$ \\
\hline $\mathbf{1}$ & 5 & 63 \\
2 & 30 & $>200$ \\
cerulenin & 0.9 & 1.25 \\
\hline
\end{tabular}

${ }^{\text {a }}$ Against $C$. lagenarium .

C. lagenarium of $\mathbf{1}$ and $\mathbf{2}$ were measured. The $\mathrm{IC}_{50}$ and MIC values are listed in Table 1. The activity of cerulenin, ${ }^{12)}$ an inhibitor of fatty acid synthase, was also tested. Cerulenin strongly inhibited both PKS1 and the fungal growth. On the other hand, MIC values of $\mathbf{1}$ and $\mathbf{2}$ were much higher than their $\mathrm{IC}_{50}$ values. Compound $\mathbf{1}$ inhibited PKS1 more strongly than 2 .

Next, the effect of $\mathbf{1}$ on melanin production of $C$. lagenarium was tested with an in vivo melanin induction system. ${ }^{13)}$ In the induction system, melanin biosynthesis can be induced by transferring non-melanized mycelia cultured in a potato-sucrose liquid medium containing $0.2 \%$ yeast extract to $1.2 \mathrm{M}$ sucrose solution. When 1 was added to the induction system, melanin production was inhibited dose-dependently as shown in Fig. 3. The inhibition \% of melanin production by $\mathbf{1}$ was estimated to be 0,60 and 88 at concentrations of 3,6 and $12 \mu \mathrm{g} / \mathrm{ml}$, respectively, from the values of $\mathrm{A}_{585}$ of the culture filtrate.

Abikoviromycin (1) was isolated as an antibiotic showing antiviral, antibacterial and antifungal activity., ${ }^{91}$ Dihydroabikoviromycin (2) was first identified as $\mathrm{NaBH}_{4}$
Fig. 3. Inhibition of in vivo melanin production of C. lagenarium by abikoviromycin.

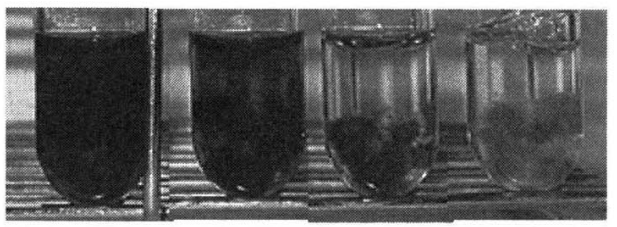
Abikoviromycin
0
3
6
12 $(\mu \mathrm{g} / \mathrm{ml})$

Melanin production was induced with or without abikoviromycin $(0 \sim 12 \mu \mathrm{g} / \mathrm{ml})$. The formation of melanin was observed at 20 hours after the induction.

reduction product of abikoviromycin, ${ }^{10)}$ and, later, it was isolated as a natural product from the culture broth of an abikoviromycin-producing strain. ${ }^{8)}$ Compound 2 showed no antibiotic activity, but its genotoxicity was reported recently. ${ }^{15)}$ In this study, we found that both $\mathbf{1}$ and $\mathbf{2}$ had PKS1 inhibitory activity and that $\mathbf{1}$ could inhibit in vivo melanin production by $C$. lagenarium without affecting the fungal growth. The inhibitory mechanism of $\mathbf{1}$ or $\mathbf{2}$ may be different from that of cerulenin. For example, they might inhibit PKS1 as an analog of an intermediate involved in the enzyme reaction. Our results demonstrated for the first time that PKS1 inhibitors are possible candidates as effective drugs for selective inhibition of melanin production of pathogenic fungi.

\section{References}

1) Kubo, Y. \& I. Furusawa: Melanin biosynthesis: Prerequisite for the successful invasion of the plant host by appressoria of Colletotrichum and Pyricularia. In The Fungal Spore and Disease Initiation in Plants and Animals. Ed., G. T. Cole et al., pp. 205 218, Plenum, New York, 1991

2) Howard, R. J. \& M. A. Ferrari: Role of melanin in appressorium formation. Exp. Mycol. 13: 403 418, 1989

3) Kurahashi, Y.: Melanin biosynthesis inhibitors (MBIs) for control of rice blast. Pesticide Outlook 12: 32 35, 2001

4) Bell, A. A. \& M. H. Wheeler: Biosynthesis and functions of fungal melanins. Ann. Rev. Phytopathol. 24: $411 \sim 451,1986$

5) Funi, I.; Y. Mori, A. Watanabe, Y. Kubo, G. Tsuji \& Y. EBIzUKA: Enzymatic synthesis of 1,3,6,8tetrahydroxynaphthalene solely from malonyl coenzyme A by a fungal iterative type I polyketide synthase PKS1. 
Biochemistry 39: 8853 8858, 2000

6) Fuji, I.; Y. Mori, A. Watanabe, Y. Kubo, G. Tsuji \& Y. EBIZUKA: Heterologous expression and product identification of Colletotrichum lagenarium polyketide synthase encoded by the PKS1 gene involved in melanin biosynthesis. Biosci. Biotechnol. Biochem. 63: 1445 1452,1999

7) Окамото, S.; M. Sakurada, Y. Kubo, G. Tsuji, I. Fujil, Y. EbizuKa, M. Ono, H. Nagasawa \& S. Sakuda: Inhibitory effect of aflastatin A on melanin biosynthesis by Colletotrichum lagenarium. Microbiology 147: 2623 2628, 2001

8) Ogawa, Y.; T. Tsuruoka, T. Shomura, H. Watanabe, S. INOUE \& T. NiIDA: On the synergism of SF-973 B and C. J. Antibiotics 26: 186 188, 1973

9) Sakagami, Y.; I. Yamaguchi, H. Yonehara, Y. OKimoto, S. Yamanouchi, K. Takiguchi \& H. SaKai: Latumcidin, a new antibiotic from Streptomyces sp. J. Antibiotics Ser. A 11: 6 13, 1958

10) Gurevich, A. I.; M. N. Kolosov, V. G. KorobKo \& V. V. ONOPRIENKO: The structure of abikoviromycin.
Tetrahedron Lett. 1968: 2209 2212, 1968

11) Kono, Y.; S. Takeuchi, H. Yonehara, F. Marumo \& Y. SAITO: The structure of latumcidin (abikoviromycin) determined by X-ray analysis. J. Antibiotics 23: $572 \sim 573,1970$

12) Nomura, S.; T. Horiuchi, S. Omura \& T. Hata: The action mechanism of cerulenin. I. J. Biochem. 71: 783 796, 1972

13) Takano, Y.; Y. Kubo, K. Shimizu, K. Mise, T. OKuno \& I. FURUSAWA: Structural analysis of PKS1, a polyketide synthase gene involved in melanin biosynthesis of Colletotrichum lagenarium. Mol. Gen. Genet. 249: $162 \sim 167,1995$

14) Umezawa, H.; T. TAZAKI \& S. FuKUYAma: An antiviral substance, abikoviromycin, produced by Streptomyces species. J. Antibiotics 5: 469 476, 1952

15) Holmalahti, J.; J. M. Paakkanen, L. Kangas \& A. von WRIGHT: Genotoxicity of dihydroabikoviromycin, a secondary metabolite of Streptomyces anulatus. Mutation Research 368: 157 163, 1996 